\title{
Influence of the Addition of Spruce Fibers to Industrial-Type High- Density Fiberboards Produced with Recycled Fibers
}

\author{
Conrad M. Sala ${ }^{1,2}$ (D) Eduardo Robles ${ }^{3}$ D $\cdot$ Grzegorz Kowaluk $^{1}$ (D)
}

Received: 30 April 2020 / Accepted: 19 September 2020 / Published online: 3 October 2020

(c) The Author(s) 2020

\begin{abstract}
The growing production of wood-based panels and the linked consumption result in a need for substituting standard wooden raw materials. The shortage of wood availability, as well as the increasing prices and a trend towards more environmentally friendly materials and processes, have encouraged the producers of wood-based products to consider extending the life cycle of wood composites. In the present work, the influence of substituting pine with spruce for industrial high-density fiberboards with 5\% of recovered fibers was studied. Samples containing 0\%, 25\%,50\%, and 100\% spruce fibers were tested in their mechanical resistance and their interaction with water. Boards from all samples met relevant standard requirements; however, the addition of spruce caused a decrease in mechanical properties, with homogeneity having the most significant influence. The modulus of rupture dropped up to $6 \%$ and the internal bond for $47 \%$ for samples having $50 \%$ of spruce. The most significant drop (50\%) was observed for surface soundness for samples made with $100 \%$ spruce. Regarding physical properties, swelling increased up to $19 \%$ with $50 \%$ spruce; on the other hand, its water absorption decreased for up to $12 \%$. The addition of spruce to industrial high-density fiberboards also influenced the formaldehyde content negatively, with an increase of up to $21 \%$ with $50 \%$ spruce.
\end{abstract}

\section{Graphic Abstract}
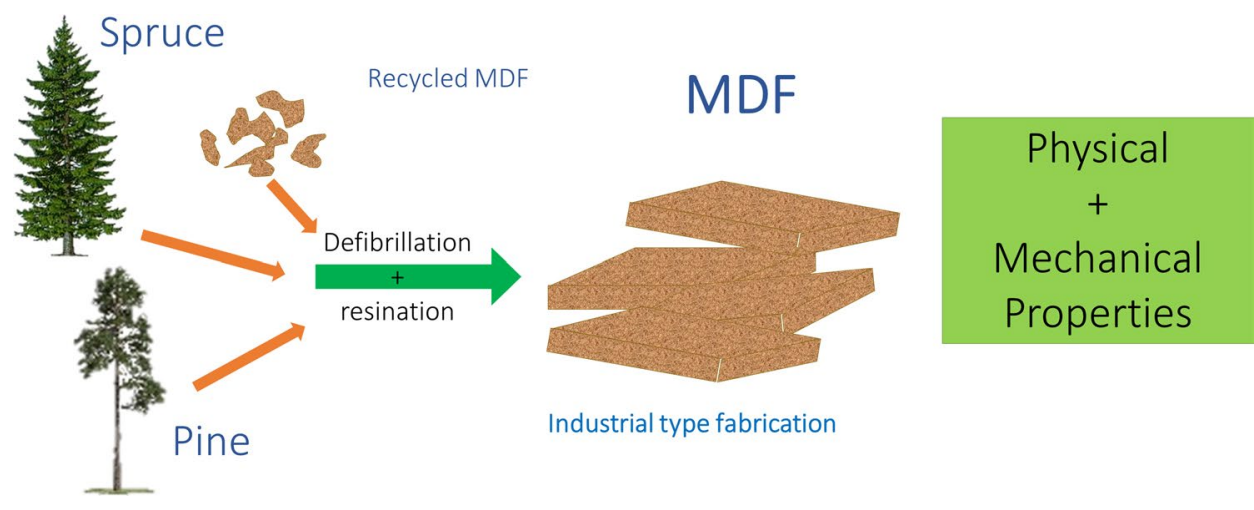

Industrial type fabrication

Keywords Wood-based panels $\cdot$ Properties $\cdot$ HDF $\cdot$ Recovered fibers $\cdot$ Recovered wood $\cdot$ Spruce

Grzegorz Kowaluk

grzegorz_kowaluk@sggw.edu.pl

Eduardo Robles

eduardo.robles@univ-pau.fr

1 Department of Technology and Entrepreneurship in Wood Industry, Warsaw University of Life Sciences - SGGW,

Nowoursynowska St. 159, 02-776 Warsaw, Poland
2 IKEA Industry Poland sp. z o. o. brand Orla, Koszki 90, 17-106 Orla, Poland

3 University of Pau and the Adour Region, Institute of Analytical and Physicochemical Sciences for the Environment and Materials (IPREM-UMR 5254), 371 Rue de Ruisseau, 40004 Mont de Marsan, France 


\section{Statement of Novelty}

The present work intends to study the properties of fiberboards as a value-added approach to spruce wood as an alternative to the current management of such wood material. The results have shown the competitiveness of spruce wood, as a suitable raw material to substitute pine wood for the production of industrial HDF.

\section{Introduction}

Wood, as a natural origin raw material, wholly ecological and renewable, becomes more popular not only in structural applications or to furniture production and interior furnishing, but also as a fuel. Due to this, the prices and availability of round wood on the market rise rapidly. Instead of solid wood, nowadays, there is a significant demand for wood-based panels, such as plywood, particleboards, or fiberboards. These materials can replace solid wood in several applications. Because of that fact, the production of these materials is increasing to meet the market demand. Medium-density fiberboard (MDF) is one of the most willingly used wood-based materials in the furniture industry [1]. Figure 1 shows the production of medium- and high-density fiberboards (MDF/HDF) over the last 18 years. From 2000 to 2018 , the fabrication of fiberboards in Europe has more than doubled from

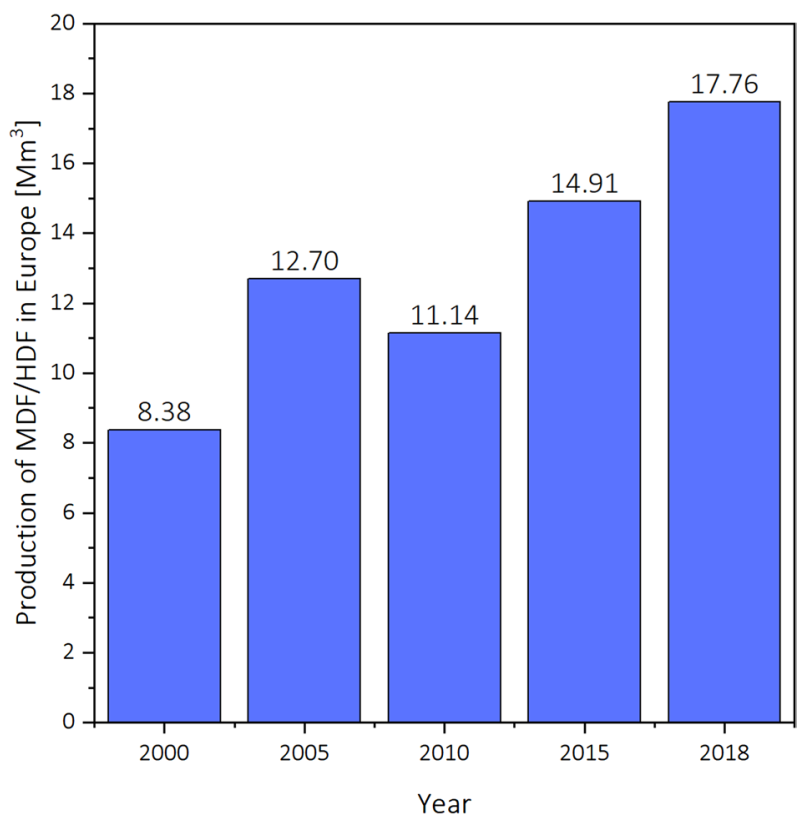

Fig. 1 Production of MDF/HDF in Europe (own evaluation based on SEO statistical data sources)
8.4 to nearly $18 \mathrm{Mm}^{3}$. Together with wood-based panels production, the need for wooden raw material was also increasing.

However, there have been studied substitutes for round wood for the production of fiberboards; nowadays, such material as recovered wood, newsprint, plantation wood species, straws, and recycled wood-based composites may be used as well [2]. In Poland, the main round wood species used for fiberboard production are pine (Pinus sylvestris L.) and spruce (Picea abies (L.) H. Karst), while adler, birch, or beech are less popular [3]. Moreover, the available forest area has increased from 6.5 million ha in 1946 to 9.2 million ha in 2018 (www.lasy.gov.pl), with the main species being pine $(70 \%)$ and spruce $(6 \%)$, the rest of species representing 24\% (www.nadlesnictwo.pl). The availability of these species has played a primary role in their selectionfor MDF production; another factor influencing this decision is the fact that pine or spruce wood anatomical structure provides good fiber quality during defibrating [4]

While forest areas in Poland are continuously increasing, the increase mentioned above on the consumption of round wood has affected its price. Based on data from the Polish State National Forest Holding, the cost of pine wood has increased by $15 \%$ from 47 in 2013 to $61 \$ \mathrm{~m}^{-3}$ in 2017 (www.e-drewno.pl). Based on a report by State Forests, the difference in the price of one $\mathrm{m}^{3}$ of pine and spruce wood varied from -1.9 in January and August 2019 to $2.4 \$ \mathrm{~m}^{-3}$ in October 2019. This increase in the price of raw wooden materials used for the production of MDF has motivated the inclusion of post-use boards into the production lines. In general, the addition of recovered fibers is negatively influencing the physical and mechanical properties of MDF [5]. However, a previous study has explored the introduction of recovered MDF up to $20 \%$ of the final composition of the composite panels, with the final products meeting relevant standard requirements [6].

The less popularity of spruce fibers to be used for the production of fibreboards is mainly due to their shorter length, but also because of a more substantial amount of unfavorable dust being produced during defibration which is caused by the spruce wood anatomy [7]. However, these properties also allow spruce fibers to be added into fiber mixes to produce boards with a better-filled structure, which also provides a smoother surface. Previous works have explored the possibility of producing MDF with black spruce tops [8], and black spruce bark [9], with the main drawback being the need for adapting the conditions of the thermomechanical refining. In another work, particleboards and MDF were made of Norway spruce bonded with melamine-urea-formaldehyde (MUF) resin, showing a high internal bond in the case of MDF. Moreover, it is even possible to consider black spruce bark as a potentially suitable raw material for MDF production, but the proper adaptation of thermomechanical 
refining conditions is required [9]. In work published by Salem, a $16 \mathrm{~mm}$ thick MDF board has more than double higher internal bond (IB) strength and nearly twice higher modulus of rupture (MOR) performance comparing to pine PB produced in the same thickness [10].

In the present study, $2.5 \mathrm{~mm}$ thick high-density fiberboards (HDF) with a $5 \%$ share of recovered HDF, bonded with MUF resin, were produced in industrial conditions. The main mechanical properties for HDF, being moduli of elasticity and rupture, internal bond, and surface soundness, were evaluated. Moreover, the performance of the surface was studied through surface water absorption, thickness swelling, free formaldehyde emissions, and surface roughness. The goal of this investigation was to determine the influence of the different amounts of spruce wood added as a raw material for producing high-density fiberboards made in industrial conditions on several fundamental mechanical and physical properties of panels as required by the appropriate standards.

\section{Experimental Section}

\section{Materials}

Pine (Pinus sylvestris L.) and spruce (Picea abies (L.) H.Karst) were obtained from Polish forests and kept at a wood yard for three months to acclimate. A commercially available melamine-urea-formaldehyde (MUF) resin was used with melamine content: $5.2 \%$, molar ratio: 0.89 , solid content: $66.5 \%$. Fibers were produced on industrial Metso Defibrator EVO56 from debarked round wood, as well as from recycled HDF (5\%) from offcuts and leftovers added to the feeding conveyor.

\section{Adjustment of Wooden Material Amount Dosage}

An exact wood mix was prepared in advance to dose the proper amount of spruce wood into the production of HDF. Depending on the sample, pine and spruce wood chips were mixed at the wood yard with a Liebherr front loader with a capacity of $30 \mathrm{t}$ per hour on a dry wood basis. Four different shares of spruce were used: $0 \%, 25 \%, 50 \%$, and $100 \%$, named P1, P2, P3, and P4, respectively. All samples contained $5 \%$ of recovered HDF from cutouts.

\section{Production of Fiberboards}

High-density fiberboards were produced at industrial conditions. Thicknesses were kept at $2.5 \mathrm{~mm}$, nominal density at $860 \mathrm{~kg} \mathrm{~m}^{-3}$ and the standard formaldehyde emission was CARB 2 compliant. The hydrothermal parameters of the defibrillator had a constant setup: preheating pressure of
$0.94 \mathrm{MPa}$, preheating temperature of $180{ }^{\circ} \mathrm{C}$, and a preheating time of $192 \mathrm{~s}$. Paraffin emulsion was added into the defibrillator milling chamber in the amount of $0.5 \%$ calculated on the weight of the oven-dry fibers. Fibers were glued in a Blow Line high-steam pressure system with the MUF resin; the amount of dry resin calculated on dry wood was $11.0 \%$. Urea content was $21.0 \%$, and ammonium nitrate (hardener) content was 3.0\%, both calculated based on the dry weight of the resin, considering a fiber mat moisture content of $10.7 \% \pm 0.7 \%$. Pressing was done with an industrial Dieffenbacher continuous press system with press factor: $5.3 \mathrm{~s}$ $\mathrm{mm}^{-1}$, press temperature $220{ }^{\circ} \mathrm{C}$, maximum unit pressure 2.5 $\mathrm{MPa}$, parameters were constant for all produced boards. The average energy consumption was $145 \mathrm{kWh}$ per each ton of dry wood. These parameters resulted in an average fiber bulk density of all samples on the level of $23.94 \mathrm{~kg} \mathrm{~m}^{-3}$.

\section{Raw Material Fraction}

The fraction of pine and spruce wood chips were examined with an IMAL vibrating laboratory sorter with nine sieves in the size of $40>20>10>8>5>3.15>1.0>0.315>0 \mathrm{~m}$ $\mathrm{m}$. For each fraction, $100 \mathrm{~g}$ of raw material was used. The set time of conducting the vibrating was 5 minutes; results correspond to an average of three examinations.

\section{Chips Moisture Content}

The chips moisture content were examined according to the oven drying method. The amount of material for each examination was $\approx 50 \mathrm{~g}$, oven temperature $103{ }^{\circ} \mathrm{C}$ and heating time from a minimum of $4 \mathrm{~h}$ to the achievement of constant weight. Results shown correspond to an average of eight examinations.

\section{Fibers Fraction}

The fraction of fibers produced with different spruce wood share were examined on ALPINE Air Jet Sieve e200LS according to DIN 66,165. Briefly, $5 \mathrm{~g}$ of totally dry wood was fractioned, with a set time of sieving of $120 \mathrm{~s}$. The selected sieves were 125, 315, 630, 1000, 1600, and $2500 \mu \mathrm{m}$. Gathered results were shown as an average of three examinations.

\section{Density}

Density was determined according to EN 323 [11], vertical density profiles of the produced HDF boards were analyzed on a GreCon DAX 5000 device following a procedure described previously [12]. 


\section{Mechanical Properties}

HDF panels were conditioned in normal conditions $\left(20{ }^{\circ} \mathrm{C}\right.$ and $65 \%$ ambient humidity) until they reached a constant weight. Then, samples were cut according to European standards [13]. The modulus of rupture (MOR) and modulus of elasticity (MOE) was determined according to EN 310 standard [14], internal bond (IB) was established according to EN 319 standards [15], and Surface soundness (SS) was determined according to EN 311 [16]. All of the mentioned mechanical properties were examined on the IMAL laboratory testing machine, with use as many as 12 test specimens of each panel type to each mentioned test.

\section{Surface Properties}

Moisture content, according to EN 322 [17] and thickness swelling (TS), according to EN 317 [18], surface water absorption was conducted accordingly to EN 382-1 [19] (each mentioned test completed on 12 test specimens of each sample). Surface roughness ( $\mathrm{Ra}$ ) was characterized with a Surtronic 25 (Taylor Hobson) profilometer, results of surface roughness presented correspond to an average from 10 measurements for each examined surface sample. Free formaldehyde content was tested thrice for each panel type according to EN 12460-5 [20] using a Hach Lange DR 3900 spectrophotometer.

\section{Statistical Analysis}

One-way analysis of variance (ANOVA) was conducted to study the effect of the above-mentioned parameters on the properties of the tested panels at the 0.05 significance level $(\mathrm{P}=0.05)$. All the statistical analyses were performed using the software of IBM SPSS Statistics 22. The results of statistical analyses are presented in Table 1.

\section{Results and Discussion}

Results of the sieving of wood chips and rHDF are shown in Table 1. Results show that the retained spruce fibers were, in general, slightly higher than the recommended values proportionated by the sieve manufacturer. It can be seen that the most significant difference could be noticed on the biggest sieve $(40 \mathrm{~mm})$ comparing pine and spruce fractions, with the difference being nearly $60 \%$ higher in spruce chips compared to pine chips. Moreover, the fraction of spruce chips on the $10 \mathrm{~mm}$ sieve was more than $15 \%$ higher than the fraction of pine chips; while on the fifth, sixth, and seventh sieves (size $5,3.15 \mathrm{~mm}$ and $<0.1 \mathrm{~mm}$ ) was accordingly $\approx 5$ and $\approx 10 \%$ higher. In the case of the fraction of pine chips on the $20 \mathrm{~mm}$ and $8 \mathrm{~mm}$ sieves, it was $\approx 13 \%$ and $\approx 6 \%$ higher than in the case of spruce chips. There was no significant differences between the average values of presented results of sieving analyses for pine and spruce chips. The moisture content of pine and spruce chips were similar, having a difference between both moisture contents of about $3 \%$, although the moisture content of spruce chips was slightly higher.

In Table 2, the fiber bulk density for each sample is presented. As can be seen, fiber bulk density differs depending on the sample; this should be taken into account for selected properties of MDF, which might be influenced [21]. Bulk density depends on diverse characteristics of wood-fibers, as fiber length and its distribution. Fibers produced from pure pine chips had fiber bulk density on the level of $23.41 \mathrm{~kg}$ $\mathrm{m}^{-3}$, and the addition of $25 \%$ of spruce chips did not influence the fiber bulk density $\left(23.38 \mathrm{~kg} \mathrm{~m}^{-3}\right)$ considerably. The

Table 2 Fibers bulk density

\begin{tabular}{lllll}
\hline & P1 & P2 & P3 & P4 \\
\hline Spruce wood share (\%) & 0 & 25 & 50 & 100 \\
Fiber bulk density $\left(\mathrm{kg} \mathrm{m}^{-3}\right)$ & 23.41 & 23.38 & 22.49 & 26.46 \\
\hline
\end{tabular}

Table 1 Sieving results for pine and spruce wood chips

\begin{tabular}{|c|c|c|c|c|c|c|c|c|c|c|}
\hline Sieves & $1^{\mathrm{a}}$ & $2^{b}$ & $3^{c}$ & $4^{\mathrm{d}}$ & $5^{\mathrm{e}}$ & $6^{e}$ & $7^{\mathrm{f}}$ & $8^{f}$ & $9^{f}$ & $\begin{array}{l}\text { Chips mois- } \\
\text { ture content } \\
(\%)\end{array}$ \\
\hline Size (mm) & 40 & 20 & 10 & 8 & 5 & 3.15 & 1 & 0.315 & $<0.315$ & \\
\hline Pine chips & 0.60 & 55.74 & 34.50 & 5.34 & 3.31 & & 0.79 & & & 46.8 \\
\hline Spruce chips & 1.38 & 48.31 & 40.94 & 5.01 & 3.47 & & 0.88 & & & 48.2 \\
\hline \multicolumn{11}{|l|}{${ }^{\mathrm{a}}<1 \%$} \\
\hline \multicolumn{11}{|l|}{${ }^{b}<45 \%$} \\
\hline \multicolumn{11}{|l|}{${ }^{\mathrm{c}}<35 \%$} \\
\hline \multicolumn{11}{|l|}{$\mathrm{d}^{\mathrm{d}}<5 \%$} \\
\hline \multicolumn{11}{|l|}{${ }^{\mathrm{e}}<8 \%$} \\
\hline${ }^{\mathrm{f}}<1 \%$ & & & & & & & & & & \\
\hline
\end{tabular}


minimum fiber bulk density was observed for P3 $(22.49 \mathrm{~kg}$ $\mathrm{m}^{-3}$ ), which was $4 \%$ less compared to P1. P4, made with $100 \%$ spruce fibers, had $12 \%$ more bulk density (the only statistically significant difference between tested samples) than $\mathrm{P} 1$, which is made of pine fibers only. Although spruce and pine wood are similar [22], having fibers of comparable dimensions like length and width [4], the influence of spruce wood on fiber bulk density is noticeable and similar to previously published works [23].

For a better understanding of the influence of the fiber share, the mass fractions of different fibers sizes are shown in Table 3. The percentage of fibers on the $125 \mu \mathrm{m}$ sieve was comparable for $\mathrm{P} 1$ and $\mathrm{P} 2$, having $62.2 \%$ and $63.1 \%$, respectively; the most significant portion was found in P3-64.8\% and the smallest in P4-60.2\%. There is a correlation between the fiber bulk density and the mass fraction shares, P1 and $\mathrm{P} 2$, having a sum of $84 \%$ and $83.7 \%$ respectively for the 125 and 15 sieves, this sum was $87.1 \%$ for $\mathrm{P} 3$ and $80.4 \%$ for $\mathrm{P} 4$, this shows an inversely proportional relationship between bulk density and the share of fiber size. Moreover, P4 had the highest sum of fibers of the last four sieves $(630,1000$, 1600 , and $2500 \mu \mathrm{m}$ ), being $19.6 \%$, while for P1, it was $16 \%$ and for P3 12.9\%. Distribution of fiber fraction influences the performance of the HDF, as it is known that mechanical properties increase with increasing fiber size, whereas physical properties decrease [24].

The density profile distribution evaluated, and the results are shown in Fig. 2, moreover, the average maximum surface layer density (SLD) and an average minimum core density (CD) are presented in Fig. 3. In Fig. 2, the left side shows the top surface, while the right side shows the bottom surface of the produced HDF. The differences between the top and bottom surface density from the samples were relatively small-on the level of 2-3\% regarding the bottom side. Based on the density profiles, it can be seen that all examined HDF boards had a similar shape that is characteristic for HDF panels [25], and there was no delamination in the middle. The highest surface density was obtained for P4, which was $1130 \mathrm{~kg} \mathrm{~m}^{-3}$, while the lowest was $1130 \mathrm{~kg} \mathrm{~m}^{-3}$, corresponding to $\mathrm{P} 3$. The surface and core densities have a different impact on final mechanical and physical performances

Table 3 Mass fraction in percent of different fibers sizes

\begin{tabular}{lrrrr}
\hline Sieve size $(\mu \mathrm{m})$ & \multicolumn{3}{l}{ Sample } & \multicolumn{1}{l}{} \\
\cline { 2 - 5 } & \multicolumn{1}{l}{ P1 } & \multicolumn{1}{c}{ P2 } & \multicolumn{1}{c}{ P3 } & P4 \\
\hline 125 & 62.2 & 63.1 & 64.8 & 60.2 \\
315 & 21.8 & 20.6 & 22.3 & 20.2 \\
630 & 8.6 & 8.8 & 6.4 & 9.7 \\
1000 & 4.8 & 4.9 & 4.4 & 6.6 \\
1600 & 2.4 & 2.4 & 2.1 & 2.9 \\
2500 & 0.2 & 0.2 & 0.0 & 0.4 \\
\hline
\end{tabular}

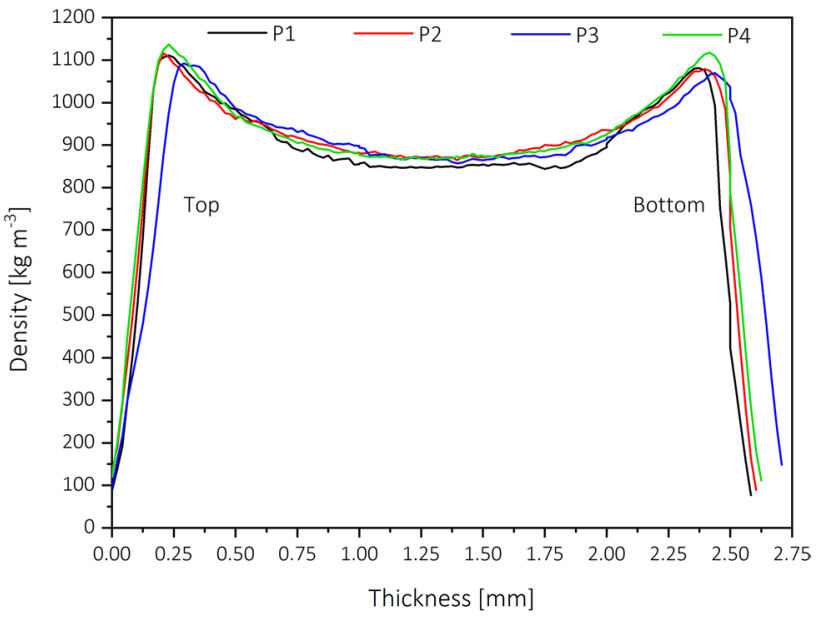

Fig. 2 Vertical density profiles of the tested panels

[26], and differences may occur due to the processing parameters [27], to avoid that, processing parameters were kept constant for the present investigation. Although the difference in minimum and maximum SLD was low (2.5\%), it might be caused by the difference in fiber bulk density, as the values concur, being the highest for P4 $\left(26.46 \mathrm{~kg} \mathrm{~m}^{-3}\right)$ and the lowest for P3 $\left(22.49 \mathrm{~kg} \mathrm{~m}^{-3}\right)$. The CD of P1 was $850 \mathrm{~kg}$ $\mathrm{m}^{-3}$, which was the lowest $\mathrm{CD}$, while $\mathrm{P} 4$ had the highest $\mathrm{CD}\left(868 \mathrm{~kg} \mathrm{~m}^{-3}\right) \mathrm{HDF}$; this means that spruce HDF was, in general, denser than pine HDF. Another factor influencing the final properties is the difference between SLD and $\mathrm{CD}$ [28]; the highest difference was for $\mathrm{P} 4(\approx 23 \%)$, while for P2, it was $25 \%$. The lowest difference was that of P3, which was slightly above $22 \%$, this means that the panels made with $50 \%$ spruce wood resulted in more homogeneous density profiles.

Figure 4 shows the modulus of rupture (MOR-bending strength) and modulus of elasticity (MOE). It can be highlighted that all the samples met the minimum MDF requirements, according to EN $622\left(>23.00 \mathrm{~N} \mathrm{~mm}^{-2}\right)$ [29]. P1

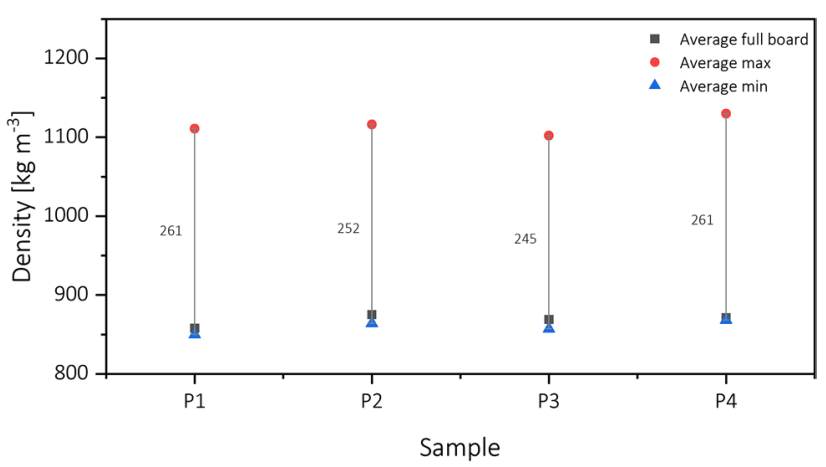

Fig. 3 HDF average maximum surface density and average minimum core density 

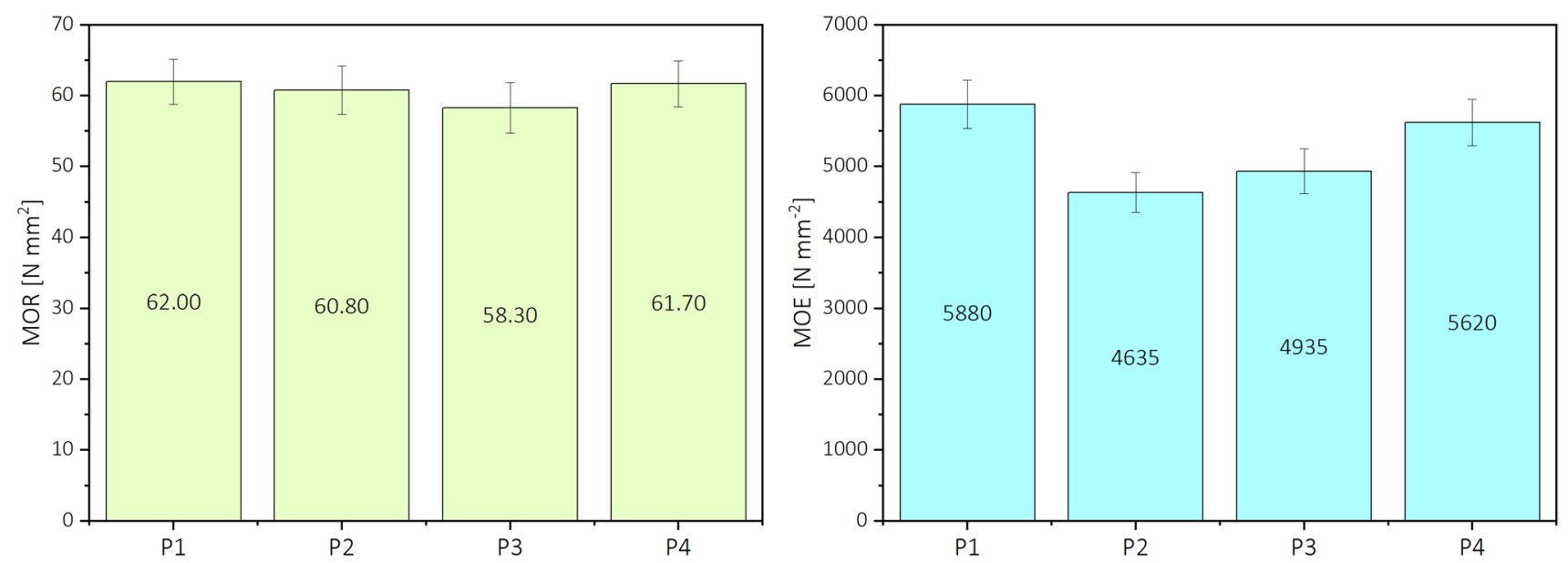

Fig. 4 Modulus of rupture and modulus of elasticity of the investigated panels

had the highest MOR $\left(62.0 \mathrm{~N} \mathrm{~mm}^{-2}\right)$, with a density of $858 \mathrm{~kg} \mathrm{~m}^{-3}$, which was within EN 622-5 requirements, as shown in Fig. 3. Although MOE and MOR are positively affected by an increase in panel density [30], boards produced with spruce had lower bending strength compared to the reference, despite having an average density of $14 \mathrm{~kg}$ $\mathrm{m}^{-3}$ lower. P2 had a slight (2\%) drop in MOR result $(60.8 \mathrm{~N}$ $\mathrm{mm}^{-2}$ ) compared with $\mathrm{P} 1$, while $\mathrm{P} 3$ had the most significant decrease of bending strength (6\%) to the level of $58.3 \mathrm{~N}$ $\mathrm{mm}^{-2}$. P4 boards had comparable MOR results $(61.7 \mathrm{~N}$ $\mathrm{mm}^{-2}$ ) to P1. From the statistical point of view, the differences in MOR average values from the samples were not significant.

While density has a major role in influencing mechanical properties, moisture content also has an impact, with higher moisture content affecting the properties of MDF negatively [31]. In this sense, although HDF boards produced with spruce had about $10 \%$ lower moisture content (4.76\%) compared to P1 (5.23\%), its influence was not observed. The most significant impact on the decrease of MOR is given by the addition of spruce fibers, rather than the moisture content [32]. It should also be noted that the lowest MOR is that of P3, where the density of surface layers (Fig. 3) was the lowest from all the tested panels. The lower MOR happens as the strain-stress distribution during bending depends mostly on the strength of the surface layers.
Similar to MOR, the highest MOE was obtained for P1 $\left(5880 \mathrm{~N} \mathrm{~mm}^{-2}\right)$, and the negative influence of spruce fibers could be observed. Modulus of elasticity result of P1 was nearly 5\% higher than $\mathrm{P} 4\left(5620 \mathrm{~N} \mathrm{~mm}^{-2}\right)$. Unlike MOR, the MOE of P3 was not the lowest, being $4935 \mathrm{~N} \mathrm{~mm}^{-2} 15 \%$ less compared to $\mathrm{P} 1$. The lowest MOE was that of $\mathrm{P} 2$, which was $4635 \mathrm{~N} \mathrm{~mm}^{-2}, 32 \%$ less than P1. This change in the tendency might be explained by the $5 \%$ lower equilibrium moisture content (see Table 4) found in P3 compared to P2 [30]. Moreover, the smallest amount of fines in P3 (as reported in Table 3) decreases the surface area of the fibers, increasing the demand for resin coverage per unit surface area [5], and the higher gluing per unit influences the mechanical properties of MDF, such as MOE positively [33]. There were statistically significant differences between average values of MOE for P1 and P2 and P3 without significant differences for P4. Similarly, there were statistically significant differences for P2 and P4, while there was no statistically significant difference of MOE between $\mathrm{P} 2$ and $\mathrm{P} 3$.

The internal bond (IB) requirement specified in EN 622-5 $\left(>0.65 \mathrm{~N} \mathrm{~mm}^{-2}\right)$ was met by all the samples, as shown in Fig. 5. The internal bond is also related to the $\mathrm{CD}$, having a directly proportional relationship. The highest IB was obtained for P1 $\left(1.33 \mathrm{~N} \mathrm{~mm}^{-2}\right)$, which was near twice the IB of P3 $\left(0.70 \mathrm{~N} \mathrm{~mm}^{-2}\right)$, where homogeneity of the wood mix was the biggest. The internal bond of $\mathrm{P} 2$ and $\mathrm{P} 4$ were
Table 4 Moisture content, thickness swelling after $24 \mathrm{~h}$, and surface water absorption of the investigated panels

\begin{tabular}{lllllll}
\hline Sample & MC $(\%)$ & SD & TS24 $(\%)$ & SD & \multicolumn{2}{c}{ WA $\left(\mathrm{g} \mathrm{m}^{-2}\right)$} \\
\cline { 5 - 7 } & & & & & Top & Bottom \\
\hline P1 & 5.03 & 0.52 & 28.79 & 1.53 & 167 & 172 \\
P2 & 4.89 & 0.40 & 33.51 & 1.62 & 176 & 180 \\
P3 & 4.68 & 0.49 & 35.68 & 1.89 & 147 & 150 \\
P4 & 4.70 & 0.43 & 32.41 & 1.83 & 198 & 173 \\
\hline
\end{tabular}



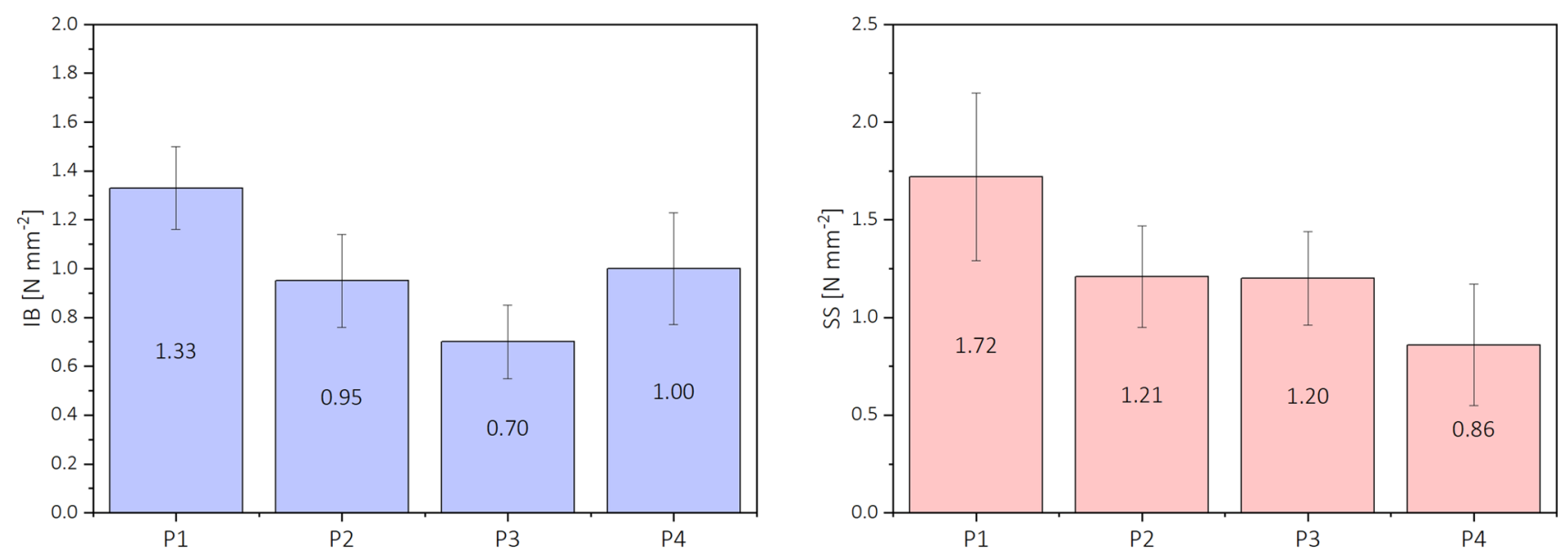

Fig. 5 Internal bond and surface soundness of the tested panels

comparable $\left(0.95 \mathrm{~N} \mathrm{~mm}^{-2}\right.$ and $1.00 \mathrm{~N} \mathrm{~mm}^{-2}$, respectively) being $\approx 30 \%$ and $\approx 25 \%$ lower compared to P1. It can be stated that not the panel core density, not the fiber bulk density, had the most significant impact on decreasing IB. On the other hand, the homogeneity of the wood mix might have the most significant impact on the final IB, with P1 samples having the highest IB [1,34]. Although adding spruce fibers caused a decrease in IB, there was a higher strength observed in samples with higher homogeneity of the wood mix (P1, P2, and P4). There was a statistically significant difference between average values of IB for $\mathrm{P} 1$ and the rest of the panels, while there were no statistically significant differences of IB average values for P2, P3, and P4 samples.

Although surface soundness (SS) minimal requirements for HDF boards are not specified by European Standards, customers demand this parameter to be $>0.80 \mathrm{~N} \mathrm{~mm}^{-2}$ [35]. Considering this, the SS was examined to evaluate the influence of spruce fibers. It can be seen that the behavior of SS was similar to that of IB. The highest SS was obtained for $\mathrm{P} 1$, being $1.72 \mathrm{~N} \mathrm{~mm}^{-2}$. Moreover, the highest SS of boards containing spruce fibers was obtained for $\mathrm{P} 4\left(1.35 \mathrm{~N} \mathrm{~mm}^{-2}\right)$, which is $\approx 22 \%$ lower than that of $\mathrm{P} 1$. The lowest SS was observed for P3 $\left(1.20 \mathrm{~N} \mathrm{~mm}^{-2}\right)$, being $30 \%$ less than P1 and $11 \%$ less than P4. P2 had a surface soundness of $1.29 \mathrm{~N}$ $\mathrm{mm}^{-2}$.

From the density profile perspective, [26] the highest performance of SS should be obtained for the highest SLD; similarly to IB, this dependence was observed only for HDF boards produced with spruce fibers (P2. P3, and P4). Although the SLD peak for P1 was one of the smallest from the samples, boards produced only from pine wood achieved the best SS. These results could mean that the most significant influence on the surface soundness was the addition of spruce fibers, as well as the homogeneity of the wood mix. The variations in SS might also be explained by differences in the anatomical structure of spruce and pine fibers, as spruce fibers have $\approx 26 \%$ smaller diameter comparing to pine fibers. Additionally, spruce fiber length is $16 \%$ shorter comparing to pine fiber length. What is more, since spruce fiber wall thickness is much thinner than pine $(2-3 \mu \mathrm{m}$ comparing to $3-11 \mu \mathrm{m})[36,37]$, the spruce pulp is about $15 \%$ stronger compared to pine pulp [38]. Apart from the panels $\mathrm{P} 1$ and $\mathrm{P} 4$, the statistical differences for SS results from the samples were not significant.

Figure 6 presents the surface roughness $(\mathrm{Ra})$ of both faces, along with the formaldehyde emissions. One of the factors influencing the use of sealing materials during lacquering is increased roughness of the HDF surface [39]. The surface roughness of $\mathrm{P} 4$ had almost the same values on both sides, while for the remaining samples, the Ra was about $6 \%$ higher in the bottom side. This difference implies that the bottom side was more "open" compared to the top side, which might lead to higher water absorption [40]. On the other hand, the most "closed" surface was achieved for P4, which had a top roughness of $2.90 \mu \mathrm{m}$, and a bottom roughness of $2.89 \mu \mathrm{m}$, these values also concur with a high surface density, with P4 having an SLD of $1130 \mathrm{~kg} \mathrm{~m}^{-3}$.

Regarding formaldehyde content, all the panels were produced complying with the CARB 2 formaldehyde emission standard, which is requiring formaldehyde content (FC) to be below $5.0 \mathrm{mg} / 100 \mathrm{~g}$, as examined by the perforator method. Moreover, all produced HDF met that California Air Resources Board standard requirement of formaldehyde content. However, it was observed an increase in FC with a mixture of pine and spruce fibers. P1 had the lowest formaldehyde content $(3.27 \mathrm{mg} / 100 \mathrm{~g})$, while the highest FC was obtained for P3 (4.15 mg/100 g), which was $21 \%$ more than P1. However, increasing spruce wood $(100 \%$, P4) did not cause a further rise in FC, but a decrease to the level of $3.42 \mathrm{mg} / 100 \mathrm{~g}$, which is $\approx 18 \%$ less than $\mathrm{P} 3$ 

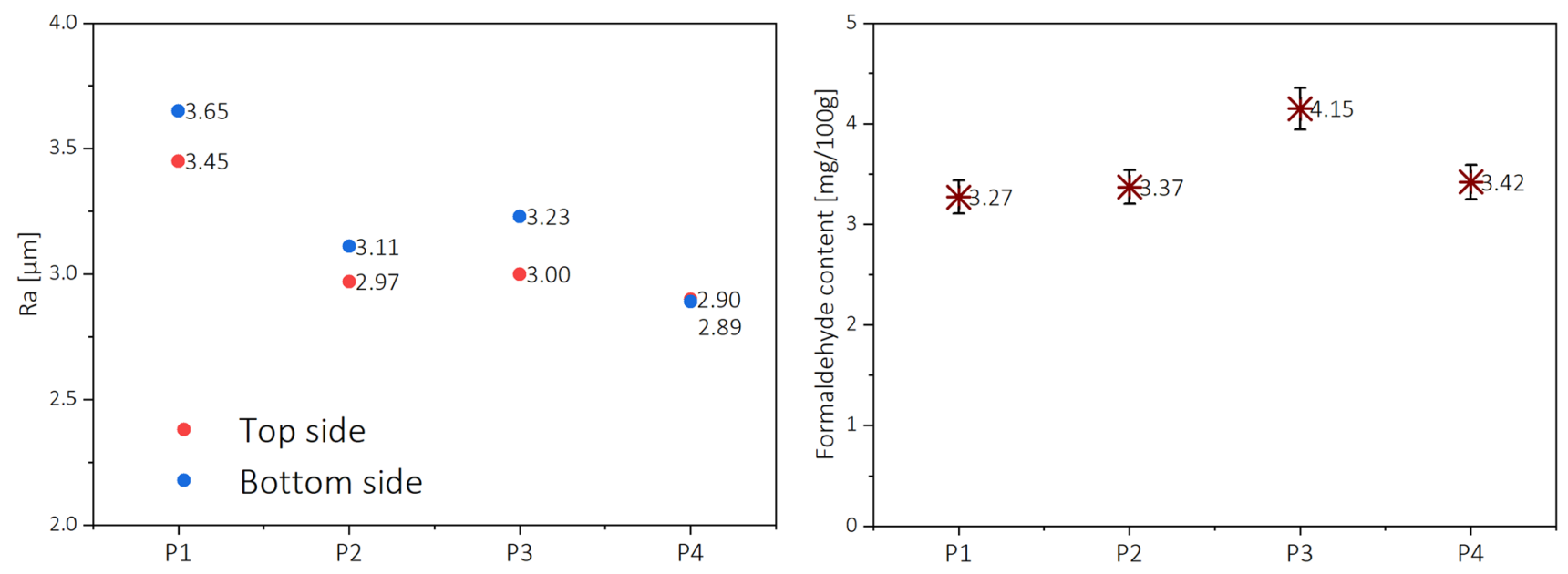

Fig. 6 Surface roughness and formaldehyde content

and $\approx 5 \%$ more than P1. P2 had formaldehyde content of $3.37 \mathrm{mg} / 100 \mathrm{~g}, \approx 19 \%$ less than $\mathrm{P} 4$, and about $3 \%$ more than $\mathrm{P} 1$. The increase in FC could be caused by the addition of spruce wood itself because, depending on the wood age, it can have higher natural formaldehyde content for about $18 \%$ than pine [41]. This is due to, in general, spruce is cut in older age than pine in Poland (www.gios.gov.pl).

Thickness swelling results are presented in Table 4. Based on EN 622-5, the maximum allowed swelling after $24 \mathrm{~h}$ for boards $<2.5 \mathrm{~mm}$ is $45 \%$; in this sense, all examined HDF samples met the demand. However, furniture companies require swelling limited to $<35 \%$ [35]. In this sense, not all board samples could satisfy this regulation. As can be observed in Table 5, the relationships between swelling (TS24) and board moisture content are inversely proportional [42]. This is because when wood-based panels moisture increases, their swelling is decreased [39].
P1 had the lowest swelling $-28.79 \%$. The lowest MC was found for $\mathrm{P} 3-4.68 \%(\approx 8 \%$ less than $\mathrm{P} 1)$, which swelling was the highest (35.68\%), being nearly $20 \%$ more than P1. TS24 was dependent on moisture content itself, but also the addition of spruce influenced swelling increase. The lowest swelling for boards produced with spruce was for P4 (32.41\%), although its equilibrium moisture content was not the highest among boards with spruce. P4 had TS24 11\% higher than P1, and 9\% lower than P3, while its $\mathrm{MC}$ was $4.70 \%$, which is comparable to MC of $\mathrm{P} 3$. However, $\mathrm{P} 2 \mathrm{MC}$ was $\approx 4 \%$ higher compared to $\mathrm{P} 3$ or $\mathrm{P} 4$, and its TS24 was very similar (32.51\%) but slightly higher than $\mathrm{P} 4$ by more than $3 \%$. What is more, the wood mix homogeneity might have a positive influence on this final HDF physical properties. From the statistical analysis, it could be found that there was a statistically significant difference between the average values of TS24 for P1 and

Table 5 Statistical analyses results ( $\mathrm{p}$ values)

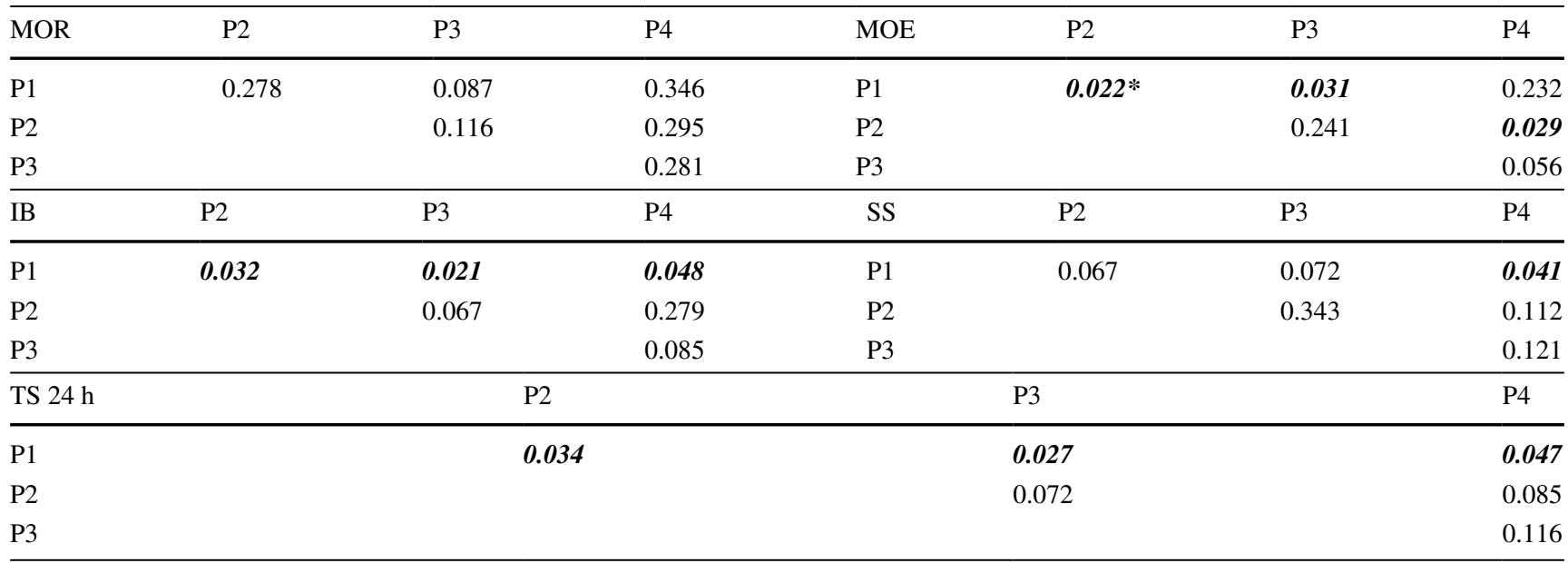

*Enhanced (bolded and italics) values ( 0.05 or below) indicate statistically significant differences 
the remaining panels. At the same time, there were no statistically significant differences in TS24 average values found for P2, P3, and P4 samples.

Results of WA (Table 4) for the bottom side of the board were mainly 2-3\% higher comparing to the top side of the board (except $\mathrm{P} 4$ where it was about $8 \%$ lower). Opposite to TS24 behavior, the minimum surface water absorption (WA) was achieved for P3 (147 $\mathrm{g} \mathrm{m}^{-2}$ for top and $150 \mathrm{~g}$ $\mathrm{m}^{-2}$ for bottom surface). However, its surface density was the smallest $\left(1102 \mathrm{~kg} \mathrm{~m}^{-3}\right)$, and MC was also the lowest $\left(4.68 \mathrm{~kg} \mathrm{~m}^{-3}\right)$. In general, WA differs from TS24. However, WA of this sample was the highest compared to other examined HDF boards for top and bottom surface, respectively $198 \mathrm{~g} \mathrm{~m}^{-2}$ and $183 \mathrm{~g} \mathrm{~m}^{-2}$, which was $36 \%$ and $18 \%$ higher compared with P3. The highest fiber bulk density $(26.46 \mathrm{~kg}$ $\mathrm{m}^{-3}$ ) might have influenced the final result. Even though moisture content of $\mathrm{P} 1$ was the highest (5.03\%), its WA was about $12 \%$ higher compared to $\mathrm{P} 3$, while $\mathrm{P} 2$ had around $16 \%$ higher WA, although P3 and P2 surface density and moisture content did not differ much. These differences could mean that spruce wood addition might have affected final surface water absorption results.

\section{Conclusions}

Industrial fibers produced from $100 \%$ spruce wood had $12 \%$ higher fiber bulk density compared to pine wood and around $19 \%$ more of fine fiber fractions. Changes in wood mix homogeneity caused a decrease of MOR up to $6 \%$ in P3. Both P1 and P4 had comparable MOR, which was 2.5 times higher than required by EN 622-5. Spruce wood addition caused decreasing in IB. The most significant drop (30\%) produced the highest wood mix homogeneity for P3. P4 had a 25\% lower IB comparing to P1. Spruce wood addition caused a decrease in SS. The most significant drop (47\%) produced the highest wood mix homogeneity for P3. P4 had a $22 \%$ lower SS comparing to P1. Spruce wood addition caused an increase in TS24. The most significant raise (19\%) produced the highest wood mix homogeneity for P3. P4 had 11\% higher TS24 compared to P1. Spruce wood addition caused an increase in WA. However, in P3, WA was decreased by $12 \%$. P4 had an average $11 \%$ higher WA comparing to P1. Spruce wood addition caused increasing in FC. The most significant raise $(21 \%)$ was observed for P3. P4 had 5\% higher FC comparing to P1. It can be concluded, that spruce wood is a suitable raw material substitute for pine wood for industrial HDF production meeting EN 622-5 standard requirements. However, the mentioned results show, that there is no straight and predictable influence of the spruce wood fibers content on the properties of HDF panels produced with use recycled fibers.
Acknowledgements E.R. wants to acknowledge the tenure track position "Biobased materials" part of E2S UPPA supported by the "Investissements d'Avenir" French programme managed by ANR (ANR16-IDEX-0002). Some of the mentioned tests have been completed within the activity of Student Furniture Research Group (Koło Naukowe Meblarstwa), Faculty of Wood Technology, Warsaw University of Life Sciences-SGGW.

\section{Funding}

Open Access This article is licensed under a Creative Commons Attribution 4.0 International License, which permits use, sharing, adaptation, distribution and reproduction in any medium or format, as long as you give appropriate credit to the original author(s) and the source, provide a link to the Creative Commons licence, and indicate if changes were made. The images or other third party material in this article are included in the article's Creative Commons licence, unless indicated otherwise in a credit line to the material. If material is not included in the article's Creative Commons licence and your intended use is not permitted by statutory regulation or exceeds the permitted use, you will need to obtain permission directly from the copyright holder. To view a copy of this licence, visit http://creativecommons.org/licenses/by/4.0/.

\section{References}

1. Ayrilmis, N., Benthien, J.T., Ohlmeyer, M.: Effect of wood species, digester conditions, and defibrator disc distance on wettability of fiberboard. J. Wood Sci. 63, 248-252 (2017). https://doi. org/10.1007/s10086-017-1620-9

2. Oniśko, W.: Nowe Generacje Tworzyw Drzewnych i Nowoczesne Technologie Oniśko. Presented (2011)

3. Nicewicz Danuta, S.C.: Technologiczne aspekty produkcji MDF (2013)

4. Lundovist, S.O., Ekenstedt, F., Grahn, T., Wilhelmsson, L.: A system of models for fiber properties in Norway spruce and Scots pine and tools for simulation. Fourth Work. IUFRO S5.01.04 Connect. between For. Resour. wood Qual. Model. approaches Simul. Softw. (2002)

5. Hwang, C.Y., Hse, C.Y.: Effects of recycled fiber on the properties of fiberboard panels. For. Prod. J. 55(1), 61-64 (2005)

6. Beele, P.: Demonstration of end uses for recovered MDF fibre. WRAP (2009)

7. Krzysik, F.: Nauka o drewnie. Państwowe Wydawnictwo Naukowe, Warsaw (1975)

8. Xing, C., Deng, J., Zhang, S.Y., Riedl, B., Cloutier, A.: Properties of MDF from black spruce tops as affected by thermomechanical refining conditions. Holz als Roh Werkst. 64, 507-512 (2006). https://doi.org/10.1007/s00107-006-0129-5

9. Cheng Xing, J., Deng, S.Y.Z.: Effect of thermo-mechanical refining on properties of MDF made from black spruce bark. Wood Sci. Technol. 41(4), 329-338 (2007). https://doi.org/10.1007/ s00226-006-0108-3

10. Salem, M.Z.M.: Norway spruce (Picea abies [L.] Karst.) as a bioresource: evaluation of solid wood, particleboard, and MDF technological properties and formaldehyde emission. BioResources 8, 1199-1221 (2013)

11. EN 323: Wood-Based Panels-Determination of Density. Brussels (1993)

12. Gumowska, A., Kowaluk, G., Labidi, J., Robles, E.: Barrier properties of cellulose nanofiber film as an external layer of particleboard. Clean Technol. Environ. Policy. 21, 2073-2079 (2019). https://doi.org/10.1007/s10098-019-01760-7 
13. EN 326-1: Wood-Based Panels. Sampling, Cutting and Inspection. Sampling and Cutting of Test Pieces and Expression of Test Results. Brussels (1993)

14. EN 310: Wood-Based Panels. Determination of Modulus of Elasticity in Bending and of Bending Strength. Brussels (1993)

15. EN 319: Particleboards and Fibreboards-Determination of Tensile Strength Perpendicular to the Plane of the Board. Brussels (1993)

16. EN 311: Wood-Based Panels—Surface Soundness-Test Method. Brussels: (2003)

17. EN 322: Wood-Based Panels-Determination of Moisture Content. Brussels (1993)

18. EN 317: Particleboards and Fibreboards-Determination of Swelling in Thickness After Immersion in Water. Brussels (1993)

19. EN 382-1: Fiberboards. Determination of Surface Absorption. Test Method for Dry Process Fiberboards. Brussels (1993)

20. ISO 12460: Wood-Based Panels-Determination of Formaldehyde Release-Part 3: Gas Analysis Method. Genevam Switzerland (2015)

21. Park, B.-D., Kim, Y.-S., Riedl, B.: Effect of wood-fiber characteristics on medium density fiberboard (MDF) performance. J. Korean Wood Sci. Technol. 29, 27-35 (2001)

22. Lundqvist, S., Grahn, T., Hedenberg, Ö: Models for fibre dimensions in different softwood species. Simulation and comparison of within and between tree variations for Norway and Sitka spruce, Scots. Proc. IUFRO \&\#8230

23. Xing, C., Zhang, S.Y., Deng, J., Riedl, B., Cloutier, A.: Mediumdensity fiberboard performance as affected by wood fiber acidity, bulk density, and size distribution. Wood Sci. Technol. 40, 637-646 (2006). https://doi.org/10.1007/s00226-006-0076-7

24. Benthien, J.T., Bähnisch, C., Heldner, S., Ohlmeyer, M.: Effect of fiber size distribution on medium-denstiy fiberboard properties caused by varied steaming time and temperature of defibration process. Wood Fiber Sci. 46, 175-185 (2014)

25. Garcia, R.A., Cloutier, ÆA., Riedl, ÆB.: Dimensional stability of MDF panels produced from fibres treated with maleated polypropylene wax dimensional stability of MDF panels produced from fibres treated with maleated polypropylene wax 39, 630-650 (2005). https://doi.org/10.1007/s00226-005-0028-7

26. Wong, E.D., Zhang, M., Wang, Q., Han, G., Kawai, S.: Formation of the density profile and its effects on the properties of fiberboard. J. Wood Sci. 46, 202-209 (2000). https://doi.org/10.1007/BF007 76450

27. Wang, S., Winistorfer, P.M., Young, T.M., Helton, C.: Step-closing pressing of medium density fiberboard; Part 1. Influences on the vertical density profile. Holz als Roh Werkst 59, 19-26 (2001). https://doi.org/10.1007/s001070050466

28. Winandy, J.E., Kamke, F.A., E.: Fundamentals of Composite Precessing Proceedings of a Workshop. Madison, WI. Gen. Tech.
Rep. FPL-GTR-149. Madison, WI: U.S. Depart ment of Agriculture, Forest Service, Forest Products Laboratory (2004)

29. EN 622: Fibreboards. Specifications. Requirements for Hardboards. Brussels (2010)

30. Cai, Z., Muehl, J.H., Winandy, J.E.: Effects of panel density and mat moisture content on processing medium density fiberboard. For. Prod. J. 56, 20-25 (2006)

31. Ganev, S., Gendron, G., Cloutier, A., Beauregard, R.: Mechanical properties of MDF as function of density and moisture content. Wood Fiber Sci. 37, 314-326 (2005)

32. David, W., Green, J.E., Winandy, and D.E.K.: Wood HandbookWood as an Engineering Material (1999)

33. Hong, M.K., Lubis, M.A.R., Park, B.D.: Effect of panel density and resin content on properties of medium density fiberboard. J. Korean Wood Sci. Technol. 45, 444-455 (2017). https://doi. org/10.5658/WOOD.2017.45.4.444

34. Ayrilmis, N.: Effect of tree species on some mechanical properties of mdf (2015)

35. PKLN-8MAACE: Swedwood International Corporate Technical Standard Specification of HDF, Version: 04 (2011)

36. Horn, R.A.: How fiber morphology affects pulp characteristics and properties of paper. Chemicals. 26(8), 39 (1972)

37. Isenberg, I.H., Revised by Harder, M.L., Louden, L.: Pulpwoods of the United States. Inst. Pap. Chem. Appleton, WI. I-Conife (1980)

38. Hatton, J.V., Cook, J.: Managed Douglas-Fir Forests: IV. Relationships Between Wood, Fibre, Pulp and Handsheet Properties (1990)

39. Carll, C.G.: Review of Thickness Swell in Hardboard Siding Effect of Processing Variables, p. 12 (1996)

40. Nicewicz, D., Monder, S.: The influence of moisture of fiber mats on the properties of MDF boards. Ann. Warsaw Univ. Life Sci.SGGW For. Wood Technol. 88, 174-177 (2014)

41. Weigl, M., Wimmer, R., Sykacek, E., Steinwender, M.: Woodborne formaldehyde varying with species, wood grade, and cambial age. For. Prod. J. 59, 88-92 (2009)

42. Trechsel, H.R., Bomberg, M.T., Carll, C., Wiedenhoeft, A.C.: Moisture-related properties of wood and the effects of moisture on wood and wood products. Moisture Control Build 54, 54-26 (2010). https://doi.org/10.1520/mnl11544m

Publisher's Note Springer Nature remains neutral with regard to jurisdictional claims in published maps and institutional affiliations. 